\title{
Placenta Percreta Causing Rupture of Uterus in Second Trimester of Pregnancy in Non Scarred Uterus with an Unusual Presentation: A Case Report and Review of Literature
}

\author{
Reena Pal*, Deepmala Prasad, Suchitra Jain \\ Department of Obstetrics \& Gynaecology, V.C.S.G.G.M.S. \& R.I., Srinagar, India \\ Email: ${ }^{*}$ pal.reena49@gmail.com
}

Received 29 June 2014; revised 23 July 2014; accepted 20 August 2014

Copyright (C) 2014 by authors and Scientific Research Publishing Inc.

This work is licensed under the Creative Commons Attribution International License (CC BY).

http://creativecommons.org/licenses/by/4.0/

\begin{abstract}
Placenta percreta causing second trimester, spontaneous uterine rupture in non high risk women is less frequent and fewer cases have been reported in the literature. We report a case of uterine rupture in second trimester of pregnancy due to placenta percreta with non specific symptoms in otherwise uncomplicated pregnancy without any high risk factors. This case report describes the case of young woman presenting second gravid with 21 weeks pregnancy with complaints of whole abdomen pain and dysuria. Ultrasonography shows single intrauterine dead fetus; placenta was fundoposterior in upper segment, a hypoechoic area seen below the placenta suggestive of abruption placentae or placenta accreta. Suddenly patient deteriorated in two hours of hospital stay, frank hemoperitoneum detected, emergency laparotomy done, per operatively whole fundal area of uterus became papery thin and cystic on touch, a small rent seen on fundal surface of uterus. The placenta was densely adhered to the fundoposterior aspect of the uterus. Patient had emergency subtotal hysterectomy. This case highlights that placenta percreta is a rare but serious complication of pregnancy which may present in early pregnancy without any associated high risk factors for placenta percreta with unusual symptoms.
\end{abstract}

\section{Keywords}

Placenta Percreta, Spontaneous Uterine Rupture, Second Trimester, Non Scarred Uterus

\footnotetext{
${ }^{*}$ Corresponding author.
} 


\section{Introduction}

Placenta percreta is a very rare complication of pregnancy that can be life-threatening for both mother and fetus. As placenta percreta induced spontaneous uterine rupture is extremely rare particularly in early pregnancy, it becomes very difficult to diagnose.

As a consequence of partial or complete absence of decidua basalis and imperfect development of the fibrinoid layer, attachment of placental villi to the myometrium is called placenta accrete. In placenta increta there is partial invasion of the myometrium where as in placenta percreta the myometrium is completely invaded. It may infiltrate not only the serosa but also neighbouring organs such as urinary bladder and bowel causing serious complication [1]. So placenta percreta is one of the most infrequent and severe forms of abnormal placentation.

Although it is an uncommon condition, it should be considered clinically significant because of life-threatening morbidity and mortality due to severe haemorrhage. Placenta percreta induced spontaneous uterine rupture in early course of pregnancy particularly in non scarred uterus without any risk factors is a very rare complication [2].

\section{Case Report}

A 28 years old woman $\mathrm{G}_{2} \mathrm{P}_{1} \mathrm{~L}_{1}$ at 21 weeks 3 days pregnancy presented with whole abdominal pain and burning micturition since ten days. Her first pregnancy was uneventful, had full term normal delivery in an institute. No history of dilatation and curettage in past, she did not have any ultrasonography in this pregnancy. On admission she was hemodynamically stable, mild pallor and ill looking. On per abdominal examination uterus was 20 - 22 weeks size, relaxed, non tense, non tender. USG showed single intrauterine dead fetus, placenta fundoposterior upper segment with a hypoechoic area seen below the placenta suggestive of abruption placenta or placenta accreta. Patient's condition suddenly deteriorated in two hours of hospital stay. On examination exact fundal hight could not be made out, guarding and rigidity was present in all over the abdomen. On paracentesis frank blood came out and emergency laparotomy was done. Intraoperatively, haemoperitonium of two liters was obtained. Whole fundal area of uterus became papery thin and cystic on touch, a rent of $4 \times 3 \mathrm{~cm}$ was seen on fundoanterior surface of uterus which was bleeding, rent area extended and fetus delivered out, cord clamped and cut (Figure 1). The placenta was densely adherent to the fundal aspect of the uterus. The myometrium and serosa

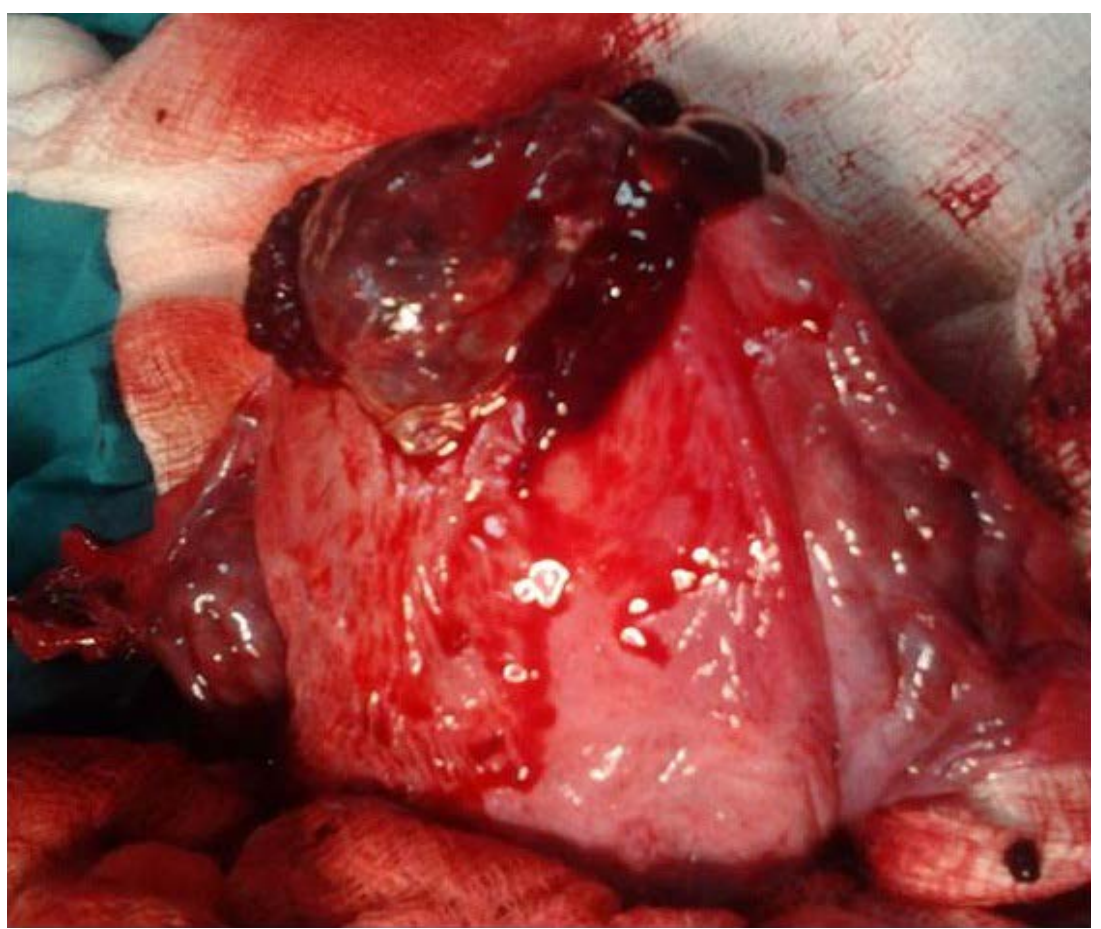

Figure 1. Amniotic membrane seen bulding through the ruptured part of the fundoanterior area of uterus. 
was completely infiltrated by placenta. The diagnosis of placenta percreta was made and the patient had emergency subtotal hysterectomy. Six units of whole blood and four units fresh frozen plasma were transfused. Postoperatively she was kept in ICU on ventilator for three days and she was discharged after ten days of hospital stay. The histopathology report showed chorionic villi invading the myometrium up to the serosa consistent with the diagnosis of a placenta percreta.

\section{Discussion}

Placenta percreta is the most extreme form of placenta accreta and is a rare but causing serious life-threatening complications to both mother and fetus. Incidence of placenta accreta, increta and percreta is varies between 1 in 540 and 1 in 93000 with an average of 1 in 700 [1] [3]. Although these complications were already known to the ancients, the first reported case in modern literature comes from Plater in 1588 [4]. But still, precise etiology of placenta accreta is unknown.

Most common predisposing factor of abnormal placentation is previous Caesarian section. Other factors are of prior uterine scars such as uterine curettage, myomectomy, Asherman's syndrome, iatrogenic uterine perforation, manual removal of the placenta, placenta previa and advanced maternal age [5] [6]. Recently, incidence of placenta accreta is on rise due to increased number of caesarean section and advanced maternal age in modern obstetrics [1] [7]. In vitro fertilization is one of the high risk factor for abnormal placentation may be considered as one of reason for increase incidences of placenta percreta in modern scenario [8] [9].

Spontaneous uterine rupture in early gestation is extremely rare. After detailed review of literature we found, few cases of spontaneous uterine rupture as a result of placenta percreta during early pregnancy have been reported but amongst them only fewer cases are reported with non scarred uterus [2] [10]-[12]. But till now only one case has been reported without any high risk factor for placenta percreta leads to spontaneous rupture of uterus in second trimester of pregnancy, apart from this case [13].

Spontaneous rupture of the uterus due to placenta percreta is one of the most urgent obstetrical complications resulting in rapid exsanguination leading to severe maternal and fetal morbidity and mortality which is more commonly seen in the third trimester and is very rarely seen in second trimester [14]. Important differential diagnoses in suspected cases when placenta could not be separated in postpartum includes retained incarcerated placenta, adherent placenta and choriocarcinoma. Histopathology has been found to be the gold standard of making the final diagnosis [11].

In this case placenta percreta presented with unusual and nonspecific symptoms like pain in whole abdomen and dysuria in early pregnancy with no other high risks, constitutes a particular challenge for clinician as prompt surgical management are essential as massive blood loss can be life-threatening to patient. Only one case has been reported in literature with similar unusual clinical presentation of dysuria in placenta percreta [15].

Antenatal ultrasound is the technique of choice used to establish the diagnosis and guide clinical management as it is cost-effective and popular. If the ultrasound findings are suspicious or the placenta is located on the posterior wall, magnetic resonance imaging can be performed. It provides crucial information on the vascularization (angioresonance) of the anatomic planes and of the degree of invasion, modifies the surgical strategy. The contrasted study by MRI has allowed the correct clinical and radiological differentiation between placenta accreta and percreta [16] [17]. Other than the imaging methods, elevated biochemical markers in maternal serum such as unexplained elevated levels of alpha fetoprotein and maternal serum creatinine kinase has been reported to be associated with an increased risk of placenta accrete [18] [19].

Placenta percreta can be managed in two ways, first is surgical removal of the uterus and the surrounding tissues and another is conservative therapy including localized resection of the placental implantation site, over sewing, blunt dissection and packing techniques. The choice between hysterectomy and conservative therapy is dependent on the severity of the placenta percreta and associated complications [20].

\section{Conclusion}

Placenta percreta induced uterine rupture in second trimester of pregnancy is extremely rare and difficult to diagnose especially in non high risk women. It may leads to massive life-threatening haemorrhage; early diagnosis and prompt surgical management might reduce maternal morbidity and mortality. This case report suggests that high index of suspicion should be considered in patients with or without risk factors and unusual symptoms. 


\section{References}

[1] Khong, T.Y. (2008) The Pathology of Placenta Accreta, a Worldwide Epidemic. Journal of Clinical Pathology, 61, 1243-1248. http://dx.doi.org/10.1136/jcp.2008.055202

[2] LeMaire, W.J., Louisy, C., Dalessandri, K. and Muschenheim, F. (2001) Placenta Percreta with Spontaneous Rupture of an Unscarred Uterus in the Second Trimester. Obstetrics Gynecology, 98, 927-935. http://dx.doi.org/10.1016/S0029-7844(01)01580-0

[3] Breen, J.L., Neubecker, R., Gregori, C.A. and Franklin, J.E. (1977) Placenta Accreta, Increta, and Percreta. A Survey of 40 Cases. Obstetrics Gynecology, 49, 43-49.

[4] Harer, W.B., et al. (1956) Placenta Accreta; Report of Eight Cases. American Journal of Obstetrics Gynecology, 72, 1309-1321.

[5] Lamyman, M.J., Mannor, H. and Brown, R. (2005) Abdominal Pain and Dysuria in Pregnancy: Urinary Tract Infection or Life Threatening Haemorrhage? Emergency Medicine Journal, 22, 918-927. http://dx.doi.org/10.1136/emj.2004.017905

[6] Neyazi, S.M. (2013) Placenta Percreta and Uterine Rupture. Saudi Medical Journal, 34, 753-756.

[7] Ogawa, M., Sato, A., Yasuda, K., et al. (2004) Cesarean Section by Transfundal Approach for Placenta Previa Percreta Attached to Anterior Uterine Wall in a Woman with a Previous Repeat Cesarean Section: Case Report. Acta Obstetricia et Gynecologica Scandinavica, 83, 115-120. http://dx.doi.org/10.1080/j.1600-0412.2004.0033d.x

[8] Dahiya, P., Nayar, K.D., Gulati, A.J.S. and Dahiya, K. (2012) Placenta Accreta Causing Uterine Rupture in Second Trimester of Pregnancy after in Vitro Fertilization: A Case Report. Journal of Reproduction and Infertility, 13, 61-63.

[9] Medel, J.M., Mateo, S.C., Conde, C.R., Cabistany Esqué, A.C. and Ríos Mitchell, M.J. (2010) Spontaneous Uterine Rupture Caused by Placenta Percreta at 18 Weeks' Gestation after in Vitro Fertilization. Journal of Obstetrics and Gynaecology Research, 36, 170-173. http://dx.doi.org/10.1111/j.1447-0756.2009.01082.x

[10] Ble, R., Adjoussou, S. and Doukoure, B. (2011) Placenta Percreta: A Rare Etiology of Spontaneous Uterine Perforation in the Second Trimester of Pregnancy. Gynécologie Obstétrique Fertilité, 39, 11-14.

[11] Morken, N.H. and Henriksen, H. (2001) Placenta Percreta-Two Cases and Review of the Literature. European Journal of Obstetrics \& Gynecology and Reproductive Biology, 100, 112-116. http://dx.doi.org/10.1016/S0301-2115(01)00422-5

[12] Pierzynski, P., Laudanski, P., Lemancewicz, A., Sulkowski, S. and Laudanski, T. (2012) Spontaneous Rupture of Unscarred Uterus in the Early Second Trimester: A Case Report of Placenta Percreta. Ginekologia Polska, 83, 626-629.

[13] Kinoshita, T., Ogawa, K., Yasumizu, T. and Kato, J. (1996) Spontaneous Rupture of the Uterus Due to Placenta Percreta at 25-Weeks' Gestation: A Case Report. Journal of Obstetrics and Gynaecology Research, 22, 125-128. http://dx.doi.org/10.1111/j.1447-0756.1996.tb00953.x

[14] Levrant, S.G. and Wingate, M. (1996) Midtrimester Uterine Rupture. A Case Report. Journal of Reproductive Medicine, 41, 186-190.

[15] Lamyman, M.J., Connor, H. and Brown, R. (2005) Abdominal Pain and Dysuria in Pregnancy: Urinary Tract Infection or Life Threatening Haemorrhage? Emergency Medicine Journal, 22, 918-926. http://dx.doi.org/10.1136/emj.2004.017905

[16] Marcos, H.B., Semelka, R.C. and Worawattaanakul, S. (1997) Normal Placenta: Gadolinium-Enhanced, Dynamic MR Imaging. Radiology, 205, 493-498. http://dx.doi.org/10.1148/radiology.205.2.9356634

[17] Palacios, M., Claudio, M.B. and Mario, P. (2001) Differential Diagnosis of the Placental Adhesive Disorders by Contrasted Nuclear Magnetic Resonance \& Ultrasound-Placenta Accreta and Percreta. http://www.obgyn.net/ultrasound/?page=/us/placenta-accreta/placenta-accreta

[18] Oyelese, Y. and Smulian, J.C. (2006) Placenta Previa, Placenta Accreta, and Vasa Previa. Obstetrics \& Gynecology, 107, 927-941. http://dx.doi.org/10.1097/01.AOG.0000207559.15715.98

[19] Ophir, E., Tendler, R., Odeh, M., Khouri, S. and Oettinger, M. (1999) Creatine Kinase as a Biochemical Marker in Diagnosis of Placenta Increta and Percreta. American Journal of Obstetrics \& Gynecology, 180, 1039-1042. http://dx.doi.org/10.1016/S0002-9378(99)70683-6

[20] Kazandi, M. (2003) Placenta Percreta: Report of Two Cases and Review of the Literature. Clinical Experimental Obstetrics Gynecology, 30, 70-72. 
Scientific Research Publishing (SCIRP) is one of the largest Open Access journal publishers. It is currently publishing more than 200 open access, online, peer-reviewed journals covering a wide range of academic disciplines. SCIRP serves the worldwide academic communities and contributes to the progress and application of science with its publication.

Other selected journals from SCIRP are listed as below. Submit your manuscript to us via either submit@scirp.org or Online Submission Portal.
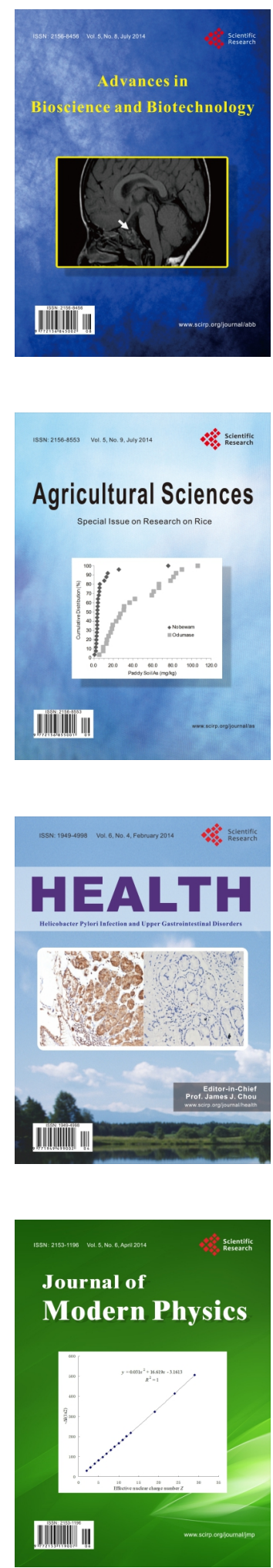
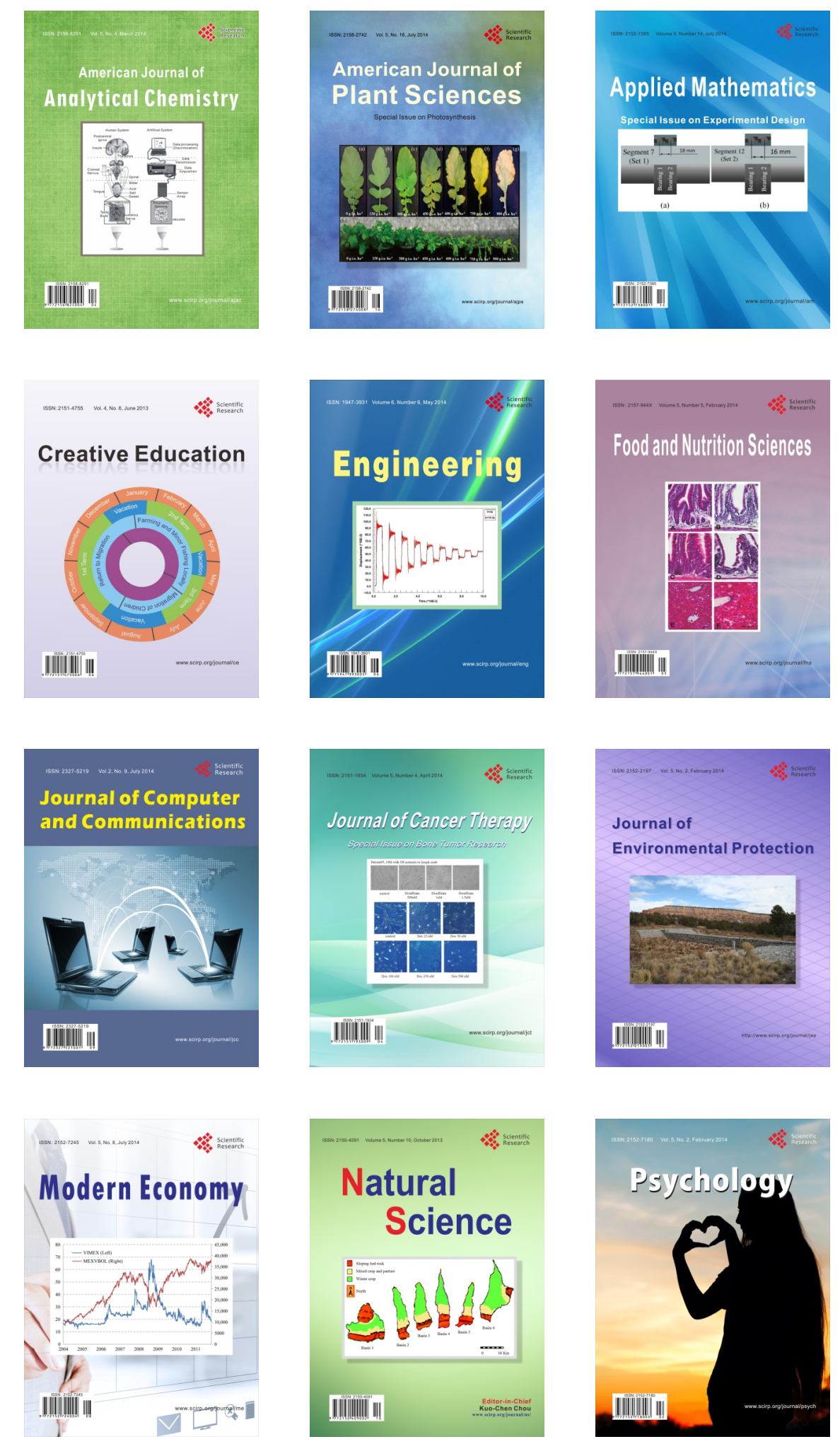